\title{
Leopoldo Zea: Eurocentrismo, colonialidade e a teoria critica latino- americana.
}

\author{
Leopoldo Zea: Eurocentrismo, colonialidad y la teoria critica en \\ latinoamerica.
}

\author{
Leopoldo Zea: Eurocentrism, coloniality and critical Latin American \\ theory.
}

\author{
Raony Valdenésio Aduci Odremán Mendes ${ }^{1}$ \\ Valdenésio Aduci Mendes²
}

\begin{abstract}
Resumo
O discurso ocidental, tão difundido enquanto ápice da modernidade pautada na racionalidade iluminista e na perspectiva universalista de civilização e etnocêntrico e excludente. É na resistência político-cultural a colonialidade imposta pela modernidade por meio da racionalidade e epistemologia que o intelectual mexicano Leopoldo Zea (1912-2004) se insere no debate intelectual latino-americano. O eurocentrismo enquanto, ideologia e processo histórico são interpretados à luz da realidade e da "concepção histórico-filosófica periférica" latino-americana e do eixo sul global. Busca-se, desta maneira, perceber a construção narrativa de uma filosofia própria para a América Latina no século XX, através do discurso de Zea, que leve em consideração à relação com regiões do mundo exploradas pelo colonialismo e o capitalismo. A metodologia utilizada será a leitura estrutural e analítica dos textos originais do filósofo em questão, e sua confrontação com os trabalhos desenvolvidos pelo grupo colonialidade $\square$ decolonialidade. Os conceitos selecionados ao longo da argumentação Zeana buscarão responder e evidenciar quais as problemáticas discutidas em torno da modernidade, eurocentrismo e seu impacto na filosofia latino-americana.
\end{abstract}

Palavras-Chave: Leopoldo Zea, Eurocentrismo, Colonialidade, Decolonialidade.

\section{Resumen}

El discurso occidental, mientras cumbre de la modernidad está guiado por la racionalidad iluminista y es un discurso etnocéntrico y excluyente, pues se traduce en la perspectiva universalista de civilización. Es en la resistencia político-cultural a la colonialidade impuesta por la modernidad que el intelectual mexicano Leopoldo Zea (1912-2004) esta insertado en el debate intectual latino-americano. El eurocentrismo mientras ideología y proceso histórico son interpretados a la luz de la realidad y de la "concepción histórico-filosófica periférica" latinoamericana y del eje sur-global. En este trabajo se busca percibir la construcción narrativa de una filosofía propia para América Latina en el siglo XX a través del análisis del discurso de Zea, llevándose en consideración la relación con regiones del mundo explotadas por el colonialismo y el capitalismo. La metodología utilizada será la lectura estructural y analítica de los textos originales producidos por Zea y la confrontación de sus ideas con los trabajos desarrollados por el grupo de estudios colonialidade-

\footnotetext{
${ }^{1}$ Mestrando em História do Tempo Presente na Universidade do Estado de Santa Catarina - UDESC; Vinculado ao Laboratório de Estudos Pós-Coloniais e Decoloniais - AYA/FAED; Florianópolis, Santa Catarina, Brasil; raonymendesodreman@gmail.com.

${ }^{2}$ Doutor em Sociologia Política (2011) e Mestre em Filosofia Política (2006) pela Universidade Federal de Santa Catarina - UFSC; Professor Doutor no Centro Universitário Municipal de São José - USJ; Florianópolis, Santa Catarina, Brasil; email: valdenesio@gmail.com. Trabalho apresentado no I Seminário Latino-Americano de Estudos em Cultura - SEMLACult, Foz do Iguaçu/PR, Brasil, 2017.
} 
decolonialidad. Los conceptos seleccionados del autor buscan poner en evidencia las problemáticas discutidas alrededor de la modernidad, el eurocentrismo y su impacto en la filosofía en latinoamericana.

Palabras claves: Leopoldo Zea, Eurocentrismo, Colonialidad, Decolonialidad.

\begin{abstract}
The Western discourse, so widespread as an apex of modernity based on the enlightenment rationality and the universalist perspective of civilization and ethnocentric and excluding. It is in political-cultural resistance the coloniality imposed by modernity through the rationality and epistemology that the Mexican intellectual Leopoldo Zea (1912-2004) is inserted in the Latin American intellectual debate. Eurocentrism as ideology and historical process are interpreted in the light of reality and the Latin American "historical-philosophical conception" and the global south axis. In this way, the narrative construction of a proper philosophy of Latin America in the twentieth century is sought through the discourse of Zea, which takes into account the relationship with regions of the world exploited by colonialism and capitalism. The methodology used will be the structural and analytical reading of the original texts of the philosopher in question, and his confrontation with the works developed by the coloniality group. The concepts selected throughout the argumen of Zea will seek to answer and highlight the issues discussed about modernity, Eurocentrism and its impact on Latin American philosophy.
\end{abstract}

Key words: Leopoldo Zea, Eurocentrism, Coloniality, Decoloniality.

\title{
1. Introdução
}

O discurso ocidental, difundido enquanto ápice da modernidade está pautado na racionalidade iluminista e na perspectiva universalista de civilização que foi se constituindo em discurso e prática etnocêntrico e excludente ao longo de séculos. Percebe-se que o projeto de modernidade, ancorado nos ideários de liberdade, igualdade e racionalidade não se efetivou para uma ampla parcela da humanidade, já que segundo esta mesma racionalidade, fundamentada em preceitos raciais, étnicos, nacionalistas, de gênero e de cultura, haveria seres humanos superiores a outros. Por si só, o projeto de modernidade concebido e expandido pela Europa se funda a partir de suas contradições inerentes, pois o mesmo não existe sem sua outra face da mesma moeda, a saber: o colonialismo (Mignolo, 2008). A mesma modernidade que visa superar em solo europeu o que havia de "tradição" é a que nega em outros cantos do planeta os ideais que a sustentaram, transformando-se mais tarde em sinônimo de genocídios epistemológicos, políticos, econômicos e ecológicos.

O século XX, de maneira geral, é significativo para os países periféricos do mundo, pois estaria possibilitando aos mesmos um novo olhar sobre o passado para entender o presente, resignificando, dessa forma, os modelos de existência ocidentais. Passa-se, a partir de então, a legitimar conhecimentos e culturas ancestrais, tradicionais, populares, locais que foram deslegitimados e inviabilizados durante o longo processo de colonização em diversas partes do planeta. Nacionalismos e regionalismos em sociedades ex-colônias são fenômenos societários que visam à sua maneira a autodeterminação e fomento de outra visão de mundo 
para os povos que não se enquadram no único modelo de racionalidade ocidental, colocando em xeque o projeto europeu de modernidade.

Do ponto de vista latino-americano, a teorização sobre a noção de crise para a construção cultural ganha fôlego nos trabalhos de Jorge Larrain Ibañez, para quem, na história latino-americana existiram momentos existenciais em que a pergunta pela identidade cultural adquiriu relevante importância. Segundo o autor,

Esses momentos foram justamente de independência das colônias hispanoamericanas; o contexto da Primeira e Segunda Guerra Mundial, e por fim, na segunda metade do século XX, quando o fracasso do populismo e o acirramento dos regimes de força ditatoriais assolaram a América Latina (LARRAIN, 1996, p.130).

O conceito de cultura passou a abranger em uma só palavra "todas as possibilidades de realização humana, além de marcar fortemente o caráter de aprendizado da cultura em oposição à ideia de aquisição inata, transmitida por mecanismos biológicos" (Laraia, 1986, p. 25). Desta forma, a cultura e o saber tornam-se o meio pelo qual os povos e as minorias dominadas irão resistir aos imperativos dominantes, sendo a identidade cultural um dos meios estratégicos de resistência mais relevantes na contemporaneidade. É através desta tensão politico-cultural e contra hegemônica ao mito da "história única" e ao projeto de modernidade eurocêntrico, que o intelectual mexicano Leopoldo $\mathrm{Zea}^{3}$ se insere, assim como vários outros pensadores de regiões periféricas do mundo, tendo como suporte para a teoria critica contemporânea, a crise da racionalidade, dos modelos e paradigmas que constituíram ao longo da modernidade a visão de mundo eurocêntrica e excludente do ocidente.

Este artigo tem como objeto de análise a concepção de eurocentrismo na perspectiva de Leopoldo Zea, bem como a possível superação deste modelo través de uma teoria/postura critica latino-americana perante a epistemologia ocidental. O trabalho de pesquisa também procura entender se na perspectiva de Leopoldo Zea haveria a possibilidade de outra modernidade não excludente, xenofóbica e etnocêntrica; e além do que, analisar em que

\footnotetext{
${ }^{3}$ Leopoldo Zea nasceu em 1912 na Cidade do México e morreu em 2004 na mesma cidade. Foi professor de filosofia da Universidad Nacional Autonoma del México, Secretário de Relações Internacionais do México, Diretor do Centro de Estudos latino-americanos, fundou e dirigiu diversas organizações (Comité de Historia das Ideas; SOLAR; FIEALC e CCyDEL), publicou mais de 50 livros e 180 artigos e ensaios, recebeu inúmeros prêmios e vários títulos de Doutor Honoris Causa em diversas universidades do mundo (Grécia, França, Espanha, Rússia, Cuba, Venezuela, Argentina, Uruguai).
} 
medida o pensador mexicano se aproxima na atualidade das pesquisas desenvolvidas pelo grupo modernidad/colonialidad ${ }^{4}$.

O conhecimento das reflexões dos intelectuais se dará mediante a leitura estrutural e analítica dos textos originais dos pensadores em questão. Somente a leitura crítica de tais obras nos permitirá conhecer importantes argumentos desenvolvidos por ambos. Segundo Carlos Altamirano (2007, p.11), “a história intelectual privilegia certa classe de fatos - em primeiro lugar, os fatos do discurso - porque eles dão acesso a uma decifração da história que não pode ser obtida por outros meios e porque proporcionam pontos de observação únicos sobre o passado".

Para atingir os objetivos expostos caminharemos em duas direções: em primeiro lugar conhecer as reflexões e as críticas de Leopoldo Zea no que diz respeito ao eurocentrismo, a modernidade excludente e ao colonialismo. Em segundo lugar, colocar em evidencia as discussões desenvolvidas pelos intelectuais latino-americanos que compõem o grupo modernidad/colonialidad. E por fim, busca-se confrontar as noções e discursos desenvolvidos por Zea, Quijano, Lander e Castro-Gómez para então, perceber em quais pontos da argumentação convergem ou divergem.

\section{Leopoldo Zea e o diálogo com os Estudos Decoloniais}

De acordo com Leopoldo Zea, "los representantes de la modernidad, por supuesto, tanto en Europa como en América, se encargaron de hacer sentir su superioridad física y cultural dentro del mundo por ellos creado" (1965, p. 28). A análise desta passagem nos faz perceber que a visão de mundo do ocidente parte de um discurso provinciano europeu que vai se revestindo na modernidade de uma ideologia "universalista" mediante processos de expansão política, econômica e cultural nas mais diversas regiões em que o homem europeu se fez presente, resultando, na realidade, em processos históricos e sociais saturadas de violência simbólica e etnocêntrica. É nesse sentido que o filósofo colombiano Santiago Castro-Gómez define a modernidade como uma "máquina geradora de alteridades que, em

\footnotetext{
${ }^{4}$ O Grupo Modernidade/Colonialidade foi sendo gradativamente formado através de vários seminários, diálogos e publicações. No ano de 1998, um significativo encontro apoiado pela CLACSO, realizado na Universidad Central de Venezuela, uniu pela primeira vez Edgardo Lander, Arthuro Escobar, Walter Mignolo, Enrique Dussel, Anibal Quijano e Fernando Coronil. A partir deste seminário, foi lançada em 2000, uma das principais publicações coletivas do grupo Modernidade/Colonialidade intitulado: La colonialidad del saber Eurocentrismo y ciências sociales, organizado por Edgardo Lander.
} 
nome da razão e do humanismo, exclui de seu imaginário a hibridez, a multiplicidade, a ambiguidade e a contingência das formas de vida concretas" (CASTRO-GÓMEZ, 2005, p. 169).

Fenômenos como os da Guerra Fria, as lutas pela independência em África e Ásia. A crítica ao imperialismo, ao colonialismo e a razão instrumental ocidental, despontam como as contestações atuais ao eurocentrismo e são fruto de processos históricos importantes na desconstrução do artifício discursivo da razão, da universalidade, da civilização, da modernidade como modelos a serem seguidos. Todas essas transformações apontam para uma passível reconstrução e releitura das histórias, culturas e modos de existir de cada povo humano. Para os europeus sua etnia é o que mostra a sua superioridade cultural e é o fator onde está assentado o eurocentrismo, o dualismo e a negação do outro. Segundo Leopoldo Zea,

\begin{abstract}
A etnia é acidental, mas é esta etnia que pode impedir o bom uso da razão. O estado primitivo dos não-europeus mostra o uso diferente da razão que tais homens fizeram. A mesma razão, em europeus e não-europeus, mostra que algo impede um uso semelhante da mesma em uns e outros. A diferente cor da pele, a forma do cérebro, parece afetar o uso da razão em uns e outros. A mesma razão alojada em corpos tão distintos dá resultados distintos, que distinguem a civilização do primitivismo ou da selvageria. A etnia, que parece ser acidental, resulta ser determinante do bom ou mau uso da razão. Desta forma, o acidental transforma-se em essencial. O determinante é a etnia, uma desigualdade mais difícil de superar que a estabelecida entre civilização e barbárie. O bárbaro podia superar sua barbárie apreendendo bem a linguagem da civilização; o selvagem terá de modificar seu corpo, sua natureza, ser outro, diferente, do que é para que use a razão de forma que o iguale com os que, por natureza, fazem bom uso dela. É uma desigualdade que acabará sendo insuperável (Zea, 2005, p.283).
\end{abstract}

As análises de Anibal Quijano sobre o processo da colonialidade do poder na América Latina convergem, em muitos sentidos, com de Leopoldo Zea. Quijano defende que o fator racial (que para Zea é sinônimo de etnia) constrói dois mitos discursivos que sustentam a dominação simbólica do eurocentrismo, como a perspectiva hegemônica de racionalidade. A saber, o dualismo, que está presente no desenvolvimento de noções dicotômicas que decorrem desse evolucionismo, utilizadas com fins "ideológicos", tais como: "pré-capital-capital, não europeu-europeu, primitivo-civilizado, tradicional/moderno etc.” (QUIJANO, 2005, p. 250). E o evolucionismo, como uma noção que encara gênero humano como uma totalidade que tem seu principio em um estado de natureza selvagem - correspondente, muitas vezes, à condição indígena e africana - e a sua culminação na sustentação da razão europeia, civilizada, liberal, capitalista. Segundo Quijano, 
Um, a ideia-imagem da história da civilização humana como uma trajetória que parte de um estado de natureza e culmina na Europa. E dois, outorgar sentido às diferenças entre Europa e não-Europa como diferenças de natureza (racial) e não de história do poder. Ambos os mitos podem ser reconhecidos, inequivocamente, no fundamento do evolucionismo e do dualismo, dois dos elementos nucleares do eurocentrismo (QUIJANO, 2005, p. 238).

A "colonialidade do poder" coincide com a "colonialidade do saber", no momento em que esses alicerces do saber tornam-se predominantes e utilizadas tanto nas áreas centrais como nas áreas periféricas do globo. Tais conceitos nos servem como modelos explicativos que anseiam apontar o conteúdo simbólico de dominação sobre o qual se ancorou a epistemologia europeia que se tornou hegemônica através dos diversos colonialismos que o mundo verificou especialmente a partir do século XIX, mas cujas origens remetem ao século $\mathrm{XV}$, ao processo de expansão marítima e da conquista de territórios no além-mar. Remete também a um marco temporal na periodização histórica, o desenvolvimento da era Moderna a partir de 1492, segundo uma leitura específica de Enrique Dussel, cuja matriz se dá em torno do "eu conquisto" e que antecede o "eu penso, logo existo" de Renè Descartes.

Segundo Leopoldo Zea a compreensão da história universal como história da Europa, torna a temporalidade e espacialidade do ocidente dominante, originando uma versão "única" da raça humana.

\footnotetext{
A Europa é vista como o fim dos tempos e como o princípio de todo futuro possível. O espírito conservador da história adicionará, no futuro, o que dela vai surgindo. Em uma série de infinitas absorções, absorções fáusticas, o espirito que alcança sua realização plena na Europa acrescentará infinitamente sem deixar de ser o que é: a Ásia é o passado da Europa, como a América e a África são o seu futuro. A Europa engoliu a Ásia, como seu passado, para prolongar-se na América e na África, como seu futuro. Como o Fausto de Goethe, nada lhe satisfaz. Nada há antes da Europa nem nada depois da Europa. A europa dá sentido ao passado e é a única possibilidade de futuro (Zea, 2005, p.285).
}

Essa versão única da história de raiz hegeliana exclui e separa epistemologicamente da metanarrativa universal outras culturas, imaginários, povos que não se enquadram na racionalidade ocidental. Tais exclusões e separações legitimam a contrariedade entre o homem ocidental europeu e o outro - provavelmente, todo o mundo não europeu. Se a Europa é o palco da realização da mente e da razão, o outro seria o espaço do mundano/bárbaro, da emoção. As leituras de Leopoldo Zea e Edgardo Lander se aproximam nesse ponto. Segundo Lander,

Com o início do colonialismo na América inicia-se não apenas a organização colonial do mundo mas - simultaneamente - a constituição colonial dos saberes, das 
linguagens, da memória [...] e do imaginário [...]. Dá-se início ao longo processo que culminará nos séculos XVIII e XIX e no qual, pela primeira vez, se organiza a totalidade do espaço e do tempo - todas as culturas, povos e territórios do planeta, presentes e passados - numa grande narrativa universal. Nessa narrativa, a Europa é - ou sempre foi - simultaneamente o centro geográfico e a culminação do movimento temporal. [...] Com os cronistas espanhóis dá-se início à 'massiva formação discursiva' de construção da Europa/Ocidente e o outro, do europeu e o índio, do lugar privilegiado do lugar de enunciação associado ao poder imperial [...] (LANDER, 2005, p. 26).

As áreas periféricas desse sistema colonial/capitalista teriam incorporado às definições desses paradigmas para compreenderem-se a si mesmas, em um processo íntimo de comparação ao cenário europeu, graças ao processo de colonialismo e de controle das subjetividades do ser "inferiorizado" e escravizado, devidamente descrito por Aimé Césaire e Frantz Fanon em suas obras clássicas sobre o colonialismo ${ }^{5}$. Leopoldo Zea corroborava com tal interpretação, no entanto depositava uma grande expectativa na assimilação/superação dialética do passado e na criação de um futuro de "emancipação mental" e cultural para as regiões periféricas globais. De acordo com Edgardo Lander,

Tão profundamente arraigadas estão esta noção do moderno, o padrão cultural ocidental e sua sequência histórica como o normal ou universal, que este imaginário conseguiu constranger uma alta proporção das lutas sociais e dos debates políticosintelectuais do continente latino-americano. Estas noções da experiência ocidental como o moderno num sentido universal com o qual é necessário comparar outras experiências permanecem como pressupostos implícitos, mesmo em autores que expressamente se propõem à compreensão da especificidade histórico-cultural deste continente. (LANDER, 2005, p. 37)

Leopoldo Zea se aproxima da perspectiva de Lander, todavia vai além, quando chama atenção para a "emancipação mental" e para a integração dos povos latino-americanos e subalternizados do mundo, através da assunção da sua realidade cultural e filosófica concreta e da construção de identidades que orientem projetos emancipatórios de futuro das culturas subalternizadas no interior da lógica instrumental ocidental. O movimento de emancipação e valorização das culturas subalternizadas se dá por meio da legitimação das identidades políticas e culturais negadas e da solidariedade entre povos do hemisfério sul global.

Tal ação projeta à autodeterminação e emancipação das sociedades que em um passado recente passaram pela experiência do colonialismo como a tomada física propriamente dita dos territórios, e que na contemporaneidade passam pela experiência da colonialidade, sendo este o controle do imaginário e das subjetividades, do saber científico e

${ }^{5}$ CÉSAIRE, Aimé. Discurso sobre o colonialismo. Porto: Poveira, 1971; FANON, Frantz,. Os condenados da terra. Rio de Janeiro: Civilização Brasileira, 1968. 
da noção epistêmica dicotômica cartesiana, do poder político e da democracia representativa, da concepção ontológica do ser moderno, da perspectiva heteronormativa da sexualidade, da dominação masculina nas relações de gênero e por fim da prevalência da religião católica romana no ocidental.

A operacionalidade do conceito de colonialidade se justifica em detrimento do conceito de colonialismo, sendo este referente apenas ao domínio econômico e político ocidental no mundo moderno e aquele mais abrangente, pois incorpora outras dimensões do domínio ocidental sobre povos e culturas negadas, invisibilizadas e subalternizadas nos continentes africano, americano e asiático. Esta diferenciação é significativa, pois, após o processo de independência e da constituição dos Estados Nacionais na América Latina, a lógica da dominação se desloca: substitui-se o colonialismo externo pela colonialidade interna, já que as elites coloniais locais continuam a perdurar a exclusão das minorias nacionais que não se enquadra(v)am no modelo de civilização e racionalidade eurocêntrica. De acordo com o autor,

A contradição latino-americana entre 'civilização e barbárie' foi proposta pela mesma Europa para manipular povos. Agora, a barbárie, como o nomadismo, aparece como expressão concreta do homem necessariamente concreto; do homem de carne e osso, o homem que vive e morre e que se nega a se perder no anonimato. Tudo isto parece estar ficando claro, na Europa e no civilizado Ocidente, quando se tem consciência do aparato de atraso em que converteu a civilização frente a seus mesmos criadores. Busca-se outra forma de civilização frente a seus mesmos criadores. Busca-se outra forma de civilização que cumpra o que deveria ter sido sua obrigação moral: fazer que os homens entre si, participem juntos, em tarefas comuns, mas sem renunciar à sua própria identidade. Afirmar a igualdade a partir da própria peculiaridade. Negar-se ser uma imitação de algo que não se é, não querer ser algo distinto do que se é. Enriquecer a experiência própria com as experiências dos outros, sem, por isto, deixar de ser. Não aceitar mais justaposições, como quem sabe o que é e o que pretende ser (ZEA, 2005, p.343).

Dito isto, vê-se como estratégia de resistência e intervenção política na contemporaneidade a afirmação, a resignificação e a incorporação de identidades culturais africanas e ameríndias exteriores ao modelo cultural de Estado-nação moderno que é estático, homogeneizador e excludente. Segundo Luciano dos Santos,

O fato é que no campo da análise em que cultura é entendida como coisa dinâmica, não estática e sempre mutável, o conceito de identidade como característica do que permanece tal como é (embora possa ser percebido como múltiplo) não daria conta de explicar fenômenos que se constroem no mundo sociocultural marcado pela dinamicidade das construções simbólicas fluidas, que como tais são perenes de lutas de representações que marcam simbolicamente a identidade e delimitam poder de inclusão e exclusão. Assim na compreensão dos objetos da cultura o conceito de 
identidade não vem assumindo o sentido de idêntico, igual e permanente, mas sim do que é contraditório, múltiplo e mutável (2011, p.143).

Segundo Leopoldo Zea a afirmação da cultura negra e indígena por meio da afirmação e difusão do movimento da Negritude e do Indigenismo é fundamental para superação da subalternidade, do colonialismo e da dependência e alienação cultural. Segundo o autor,

Negritude e indigenismo são conceitos ideológicos que tem sua origem em uma situação que é comum aos homens de África Negra e Afroamérica por um lado e da Latinoamérica ou Indoamérica por o outro: a situação de dependência. Em um e em outro caso expressa a tomada de consciência de uma situação de marginalidade e subordinação que se pretende mudar. Uma situação criada pela Europa, e o chamado mundo ocidental, ao expandir-se pelo resto da terra, dominando e instrumentalizando os homens que formam parte dela. Em ambos os casos se trata de conceitos sobre o que o conquistador e o colonizador apoiaram a justificativa do que consideravam seu direito ao domínio. Estas partem de uma suposta superioridade racial e cultural por não ser negros ou indígenas. $\mathrm{O}$ negro e o indígena vêm a ser expressão do sub-humano. E por sê-lo, um simples e puro instrumento de quem se consideravam a si mesmos a máxima expressão do homem. É frente a esta presunção que os homens que sofrem tal atentado a sua dignidade alçam a bandeira da negritude e do indigenismo como expressões concretas de homem (1974, p. 57).

A afirmação ideológica, que podemos entender como política, da negritude e do indigenismo colocam em pauta a afirmação de identidades culturais e políticas que alteram a noção hegemônica do estado-nação moderna. Walter Mignolo faz uma leitura próxima à de Leopoldo Zea no que tange a importância da afirmação identitária na reformulação contemporânea da política estatal e da democracia representativa. Segundo o autor,

Não, não estou falando de 'política de identidade', mas de 'identidade em política' Não há, pois, necessidade de argumentar que a política de identidade se baseia na suposição de que as identidades são aspectos essenciais dos indivíduos, que podem levar à intolerância, e de que nas políticas identitária posições fundamentalistas são sempre um perigo. Uma vez que concordo parcialmente com tal visão de política de identidade - da qual nada é isento, já que há políticas identitária baseadas nas condições de ser negro ou branco, mulher ou homem, em homossexualidade e também em heterossexualidade -, é que construo meu argumento na relevância extrema da identidade em política. E a identidade em política é relevante não somente porque a política de identidade permeia, como acabei de sugerir, todo o espectro das identidades sociais, mas porque o controle da política de identidade reside, principalmente, na construção de uma identidade que não se parece como tal, mas como a aparência "natural" do mundo. Ou seja, ser branco, heterossexual e do sexo masculino são as principais características de uma política de identidade que denota identidades tanto similares quanto opostas como essencialistas e fundamentalistas. No entanto, a política identitária dominante não se manifesta como tal, mas através de conceitos universais abstratos como ciência, filosofia, Cristianismo, liberalismo, Marxismo e assim por diante. Irei argumentar que a identidade em política é crucial para a opção descolonial, uma vez que, sem a construção de teorias políticas e a organização de ações políticas fundamentadas em identidades que foram alocadas (por exemplo, não havia índios nos continentes americanos até a chegada dos espanhóis; e não havia negros até o começo do comércio massivo de escravos no Atlântico) por discursos imperiais (nas seis línguas da modernidade europeia - inglês, francês e alemão após o Iluminismo; e 
italiano, espanhol e português durante o Renascimento), pode não ser possível desnaturalizar a construção racial e imperial da identidade no mundo moderno em uma economia capitalista. As identidades construídas pelos discursos europeus modernos eram raciais (isto é, a matriz racial colonial) e patriarcais (2008, pp. 289290).

\section{Considerações Finais}

O artigo aqui desenvolvido é um breve esboço de questões que serão debatidas e aprofundadas na dissertação em curso sobre o pensamento de Leopoldo Zea e sua possível convergência com o pensamento decolonial latino-americano contemporâneo, e não tem a função e nem a intenção de esgotar o debate. Nessa pesquisa em andamento vemos claramente a configuração de um novo projeto intelectual para América Latina a partir de uma modernidade alternativa. Tal modernidade seria contraria ao eurocentrismo e às identidades excludentes propostas pelo estado-nação no século XIX.

Aqui não fazemos a defesa de uma homogeneidade cultural latino americana, muito pelo contrário, é a integração de culturas pelo respeito às diferenças. Superar a lógica da racionalidade ocidental é exatamente ir contra e além dos preconceitos, binarismos, hierarquização social, imperialismo cultural, desigualdade naturalizada, exploração do liberalismo econômico mundial que o ocidente nos legou e oferece como única alternativa.

O breve estudo das ideias de Leopoldo Zea e de alguns autores decoloniais, realizados até o momento, possibilita visualizar uma possível ruptura destes autores com a lógica temporal do ocidente, que é pautada na noção de progresso. Por sua vez, pode-se perceber a partir da especificidade do pensamento de Zea, a busca da assimilação e problematização do passado na tentativa de uma nova noção e projeto de futuro para América Latina, que vise o desenvolvimento de outra epistemologia para a humanidade, a integração cultural e econômica para a região. Fica visível o intuito de Leopoldo Zea, de deslocar a concepção filosófico-epistemológica de futuro da humanidade de uma noção de progresso capitalista individualizante, para uma perspectiva de integração cultural dos povos marginalizados do ocidente.

\section{Referências Bibliográficas:}

ALTAMIRO, Carlos. Ideias para um programa de história intelectual. Tempo Social: revista de sociologia da USP, v.19, $\mathrm{n}^{\circ}$ 1. Disponível em: http://www.scielo.br/pdf/ts/v19n1/a01v19n1. Acesso em: 03 jun. 2017. 
CASTRO-GÓMEZ, Santiago. Ciências sociais, violência epistêmica e o problema da "invenção do outro". In: LANDER, Edgardo (Org.). A colonialidade do saber: eurocentrismo e ciências sociais, perspectivas latino-americanas. Buenos Aires: CLACSO, 2005. p. 80-87.

DUSSEL, Enrique. 1492: o encobrimento do outro - a origem do mito da modernidade, conferências de Frankfurt. Petrópolis: Vozes, 1993.

LANDER, Edgardo. Ciências sociais: saberes coloniais e eurocêntricos. In: (Org.). A colonialidade do saber: eurocentrismo e ciências sociais, perspectivas latino-americanas. Buenos Aires: CLACSO, 2005. p. 8-23.

LARAIA, Roque de Barros. Cultura: um conceito antropológico. Rio de Janeiro: Zahar, 1986.

LARRAIN IBAÑEZ, Jorge. Modernidad, razón e identidad en América Latina. Santiago: Editorial Andrés Bello, 1996.

MIGNOLO, Walter. Desobediência epistêmica: A opção descolonial e o significado de identidade em política. Revista Cadernos de Letras da UFF - Dossiê: Literatura, língua e identidade, $\mathrm{n}^{\circ} \quad 34, \quad$ p. 287-324, 2008. Disponível em: http://www.uff.br/cadernosdeletrasuff/34/artigo18.pdf. Acesso em: 03 jun. 2017.

QUIJANO, Aníbal. Colonialidade do poder, eurocentrismo e América Latina. In: LANDER, Edgardo (Org.). A colonialidade do saber: eurocentrismo e ciências sociais, perspectivas latino-americanas. Buenos Aires: CLACSO, 2005. p. 107-130.

SANTOS, Luciano dos. As identidades culturais: Proposições conceituais e teóricas. Revista Rascunhos Culturais, Coxim/MS, v.2, nº4, p. 141 - 157, jul/dez., 2011. Disponível em: http://revistarascunhos.sites.ufms.br/files/2012/07/4ed_artigo_9.pdf. Acesso em: 03 jun. 2017.

ZEA, Leopoldo. América Latina y en mundo. Buenos Aires: Eudeba, 1965.

ZEA, Leopoldo. Negritud y Indigenismo. In: . (Org.). Dependencia y liberación en la cultura latinoamericana. Ciudad de México: Cuadernos de Joaquín Mortiz, 1974. p. 57-76.

ZEA, Leopoldo. Discurso desde a marginalização e a barbárie. Rio de Janeiro: Ed. Garamond, 2005. 488 p. 